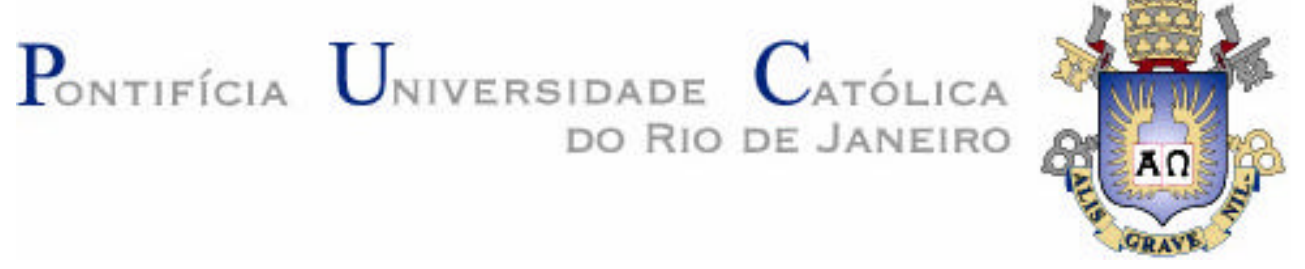

Christiani Margareth de Menezes e Silva

\title{
Catarse, emoção e prazer na Poética de Aristóteles
}

\begin{abstract}
Tese apresentada como requisito parcial para obtenção do grau de Doutor pelo Programa de Pós-graduação em Filosofia da PUC-Rio. Aprovada pela Comissão Examinadora abaixo assinada.
\end{abstract}

Orientadora: Profa. Irley Fernandes Franco

Rio de Janeiro

Outubro de 2009 


\section{Pontifícia U Uiversidade Católlica $_{\text {a }}$

"Catarse, emoção e prazer na Poética de Aristóteles"

Tese apresentada como requisito parcial para obtenção do grau de Doutor pelo Programa de Pós-Graduação em Filosofia do Departamento de Filosofia do Centro de Teologia e Ciências Humanas da PUC-Rio. Aprovada pela Comissão Examinadora abaixo assinada.

Profa. Irley Fernandes Franco

Orientadora

Departamento de Filosofia - PUC-Rio

Prof. Danilo Marcondes de Souza Filho

Departamento de Filosofia - PUC-Rio

Profa. Barbara Botter

Departamento de Filosofia - PUC-Rio

Prof. James Bastos Âreas

Departamento de Filosofia - UERJ

Prof. Edson Peixoto de Resende Filho

Departamento de Filosofia - UGF

Prof. Paulo Fernando Carneiro de Andrade

Coordenador Setorial do Centrode Teologia

e Ciências Humanas - PUC-Rio

Rio de Janeiro, 30 de outubro de 2009 
Todos os direitos reservados. É proibida a reprodução total ou parcial do trabalho sem autorização do autor, do orientador e da Universidade.

\section{Christiani Margareth de Menezes e Silva}

Graduou-se em Filosofia na Universidade Estadual de Londrina (UEL-PR) em 1997. Cursou a Especialização (Pós-Graduação Lato Sensu) em Fotografia: O Discurso Fotográfico no CECA (Centro de Educação, Comunicação e Arte da UEL) em 1998 e cursou a Especialização em Filosofia no Brasil: Aspectos Éticos e Políticos no CLCH (Centro de Letras e Ciências Humanas da UEL) em 2000-2001. Mestre em Filosofia pela Pontifícia Universidade Católica do Rio de Janeiro em 2005.

Ficha Catalográfica

Silva, Christiani Margareth de Menezes e

Catarse, emoção e prazer na Poética de Aristóteles / Christiani Margareth de Menezes e Silva; orientadora: Irley Fernandes Franco. - 2009.

194 f. ; $30 \mathrm{~cm}$

Tese (Doutorado em Filosofia) - Pontifícia Universidade Católica do Rio de Janeiro, Rio de Janeiro, 2009.

Inclui bibliografia

1. Filosofia - Teses. 2. Poética. 3. Catarse. 4. Mimese. 5. Emoções. 6. Prazer. I. Franco, Irley Fernandes. II. Pontifícia Universidade Católica do Rio de Janeiro. Departamento de Filosofia. III. Título. 


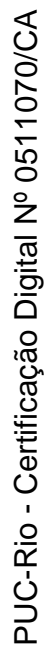

À minha mãe, pelo perseverar. 


\section{Agradecimentos}

À minha orientadora Irley Franco, pelo apoio, pelas observações e sugestões que sempre me incentivaram a buscar meu melhor;

À professora Maura Iglésias do Departamento de Filosofia da PUC-Rio, pelo material cedido e pelas observações feitas na qualificação;

Ao Departamento de Filosofia da PUC-Rio, especialmente a Diná Lúcia e Edna Sampaio. Agradeço também aos funcionários da DAR e da CCPG por toda atenção e pela gentileza com que me atenderam;

Aos colegas do NUFA/PUC-Rio, especialmente a Cristina Ribas, pelas vivas discussões e discordâncias. Aos colegas e funcionários do Departamento de Filosofia da UEL-Pr por todo o apoio na finalização da tese;

À CAPES, pela bolsa concedida o que permitiu tempo de dedicação e acesso ao material bibliográfico adequado à feitura da tese;

Ao professor Aloísio Fávaro por toda ajuda, pelas aulas de grego, pela correção, revisão do texto e pelo entusiasmo no estudo da antiguidade. Agradeço também à Juliana Aggio (USP) pelas ótimas sugestões dadas no nosso rápido encontro;

Aos amigos Jorge Vieira, Maitê Orticelli, Marta Frecheiras, Krishnamurti Jareski pelo apoio, sugestões e pelo material ao qual me permitiram acesso. Agradeço especialmente a Elaine Valente Ferreira, Juliana Martins, Maria Angélica Machini Corrêa, Kátia e Camilla Frecheiras por tudo o mais;

À minha família pela compreensão, paciência e força. E a Nino, pela suave companhia, com saudades. 


\section{Resumo}

Silva, Christiani Margareth de Menezes e, Franco, Irley Fernandes. Catarse, emoção e prazer na Poética de Aristóteles. Rio de Janeiro, 2009. 194p. Tese de Doutorado - Departamento de Filosofia, Pontifícia Universidade Católica do Rio de Janeiro.

A presente tese de doutorado trata da catarse, da emoção e do prazer na Poética de Aristóteles. O filósofo não define o que entende por catarse trágica na obra; no entanto, ele nos diz que a trama trágica suscita duas emoções dolorosas piedade e temor - e, além disso, surte um prazer que lhe é próprio. A questão é entender como estes dois opostos, prazer e dor, relacionam-se entre si e se no esclarecimento dessa relação encontramos também pistas para interpretarmos a catarse.

\section{Palavras-chave}

Poética; catarse; mimese; emoções; prazer. 


\section{Abstract}

Silva, Christiani Margareth de Menezes e; Franco, Irley Fernandes. Catharsis, emotion and pleasure in Aristotle's Poetics. Rio de Janeiro, 2009. 194p. Thesis - Philosophy Department, Pontifícia Universidade Católica do Rio de Janeiro.

The PHD thesis presented here is a reflection on the problems of catharsis, emotion and pleasure on Aristotle's Poetics. In his work, the philosopher does not define what he understands as tragic catharsis; nevertheless, he tells us that the tragic framework arouses two painful emotions - pity and fear - besides originating an inherent pleasure. The arising questions are: how can pleasure and pain, being converses, relate and if on the event of this issue being clarified will we provide hints for interpreting catharsis.

\section{Keywords}

Poetics; catharsis; mimesis; emotions; pleasure. 


\section{Sumário}

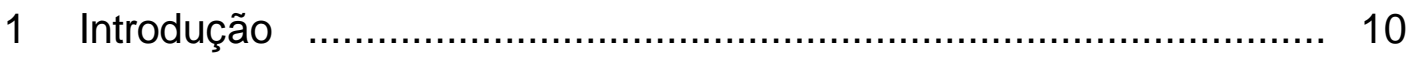

2 Os contextos da catarse ............................................................ 18

2.1. Ritos catárticos

2.2. Catarse e medicina …………………………................ 35

2.3. Platão e a catarse …………………………………...... 43

3 A Catarse no Corpus Aristotelicum ……………......................... 52

3.1. Os Tratados de Biologia ................................................. 52

3.2. A catarse nos contextos não biológicos ................................. 55

4 A noção de mimese ……....................................................... 65

4.1. A mimese na poesia trágica e cômica …………....................... 69

4.2. A mimese em Heródoto ...................................................... 75

4.3. O papel cognitivo da mimese $\quad$............................................. $\quad 79$

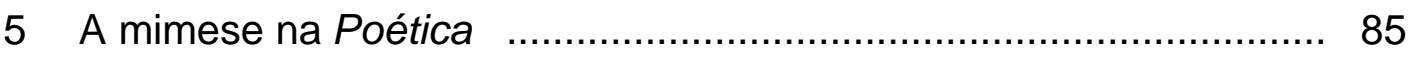

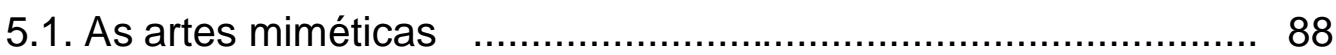

5.2. As ocorrências na obra ..................................................... 93

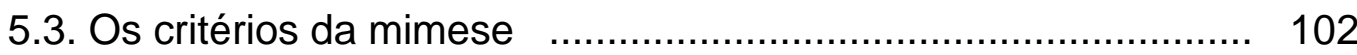

6 Acerca da emoção ............................................................... 108

6.1. Afecção enquanto emoção …............................................ 108

6.2. A dimensão cognitiva da emoção ……………………......... 118

6.3. As emoções da tragédia ................................................... 128

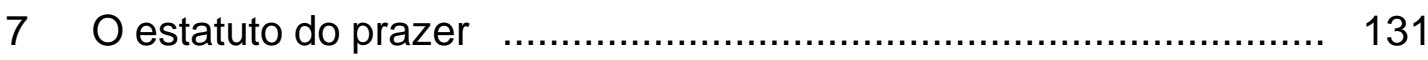

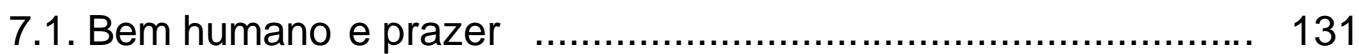

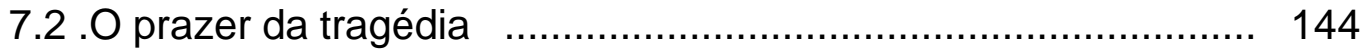

8 Catarse, emoção e prazer ………………………………...... 152

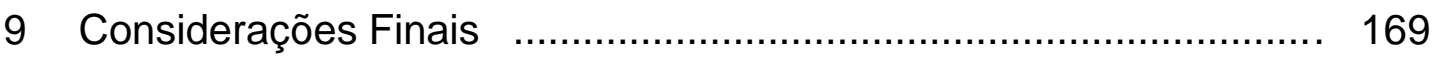

10 Referências Bibliográficas ........................................................ 172 


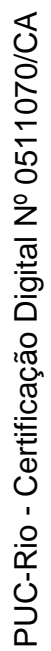

A contemplação é a poética da vida

Dorival Caymmi 